\title{
SOCIOTECHNICAL INNOVATIONS OF SHORT FOOD SYSTEMS CASE STUDY OF THE CITY REGION ILE DE FRANCE
}

\author{
H. Serhan $\bowtie$ and G. Yannou-LeBris \\ AgroParisTech, France \\ $\bigotimes$ hiam.serhan-murray@agroparistech.fr
}

\section{Abstract}

This paper relies on four case studies designed as short food systems aimed at coupling production, distribution, and consumption to contribute to the ecological transition of the City-Region Ile-deFrance. Through documentary research and interviews, we explore the growth strategies and sociotechnical innovations these short food systems implemented, and the links that can be established between these innovations, localism strategies, and the regional sustainable development.

Keywords: sustainable design, social innovation, eco-innovation

\section{Introduction}

In a world experiencing unprecedented urban growth and challenged by social, economic, environmental, and nutritional impacts of agri-food systems, examining the questions of how short food systems (SFSs) are designed to contribute to the ecological transition of cities and their surrounding territories to greater sustainability seems more important than ever. These societal challenges require systemic changes called 'sociotechnical transitions' or social and technical sustainable innovations at the three levels that design agri-food systems: First, the "food landscape" which encompasses the global pressures such as the growing population, food policies, ecosystem degradation, and health problems related to food within which action will be taken (FAO, 2018). Second, the "food dominant regime" in which actors are locked-in with established rules, standards, technologies, distribution channels and consumption behaviour that form the globalized agroindustrial food system (Rastoin and Ghersi, 2010; Fournier et Touzard, 2014; Meynard et al., 2016). Third, "food niches" that are represented by local (20 to $100 \mathrm{~km}$ radius) or SFSs operating with minimized intermediaries between producers and consumers, and developing alternative ways to produce, distribute and consume food. With these alternative practices, such as clean technologies, healthier food produced with traditional recipes and/or locally produced organic ingredients, SFSs aim re-localizing and connecting territories, agriculture and food consumption with food ecological values (European Commission, 2013).

Food transition towards sustainable systems and processes come about through interaction, coevolution and innovation between these three sociotechnical systems and can follow multiple transition paths such as reducing energy and transport impacts, repurposing food wastes and losses, increasing food nutritional values, and changing consumers' needs, wants and consumption behaviour (FAO, 2018). These paths provide societal functions and end-use services (Geels, 2004) through localism and alternative ways to produce and consume food. 


\section{Research context and contribution}

French national policy supports since decades the development of local food systems through the agrifood system transition strategy and projects (see, Serhan and Yannou-LeBris, 2020; Yannou-LeBris et al., 2019). To meet some of the requirements of the 11 million consumers in the Paris-Île-de-France region whose demand for local and sustainable products can hardly be satisfied, multiple institutions (such as Aria, Cervia) ${ }^{1}$ and programmes are empowering and encouraging existing local food firms to redesign their business models with sustainable practices. Moreover, the French 2018 Agri-Food Egalim law requires redesigning food systems activities, structures and governance with novel sociotechnical configurations for environmentally friendly, socially-inclusive, economically-viable food solutions. This policy supports the development of eco-inclusive farming systems and organic and qualitative food value chains. This context encouraged the development of two types of local food actors: established or recently renovated farms to process food, and start-ups established to transform local resources.

While agri-food researchers put an increasing emphasis on the sustainability transition of food systems (El Bilali and Probst, 2017; Meynard et al., 2016; Ingram, 2015), little work has been done to understand the technical and social innovations that emerge on a niche transition path and how these innovations contribute to regional sustainability transition.

This study is part of an ongoing project at AgroParisTech ${ }^{2}$ aimed at studying the role and impacts of SFSs on the ecological transition of Île-de-France region. In this paper, we study the sociotechnical innovations and contribution of four, and recently established (last decade) food-processing firms designed as SFSs for the region Île-de-France. To identify and analyse the impacts of their activity systems design we use the "creative practices and innovation-in-the-making' approach (Hoffman and Loeber, 2016). This approach follows situated actors in their daily actions to create, continually improve, reconfigure their activity with novel practices and networks, and scale-up their innovations. By this way we illustrate how these SFSs develop to link their activities and sociotechnical innovations with territories and how they evolve with or within the conventional food regime. This analysis captures how SFSs were designed and redesigned as they attempt to meet their mission and goals and their contexts' requirements.

This main contribution of this paper is twofold: First, to identify the social and technical innovations of SFSs in the context through which they develop. Second, to discuss the linkages of these innovations to the regional sustainability transition through "localism", and how SFSs interact and align with food regime and landscape systems to develop and scale-up.

The paper is structured as follows: Section 3 presents the theoretical framework of our work. In Section 4 we describe our research methodology. Section 5 presents the case studies; this is followed by cases analysis and conclusions.

\section{Strategies and practices for sociotechnical niche transition}

In food sustainability transition niches are vital as they are the spaces where new firms with innovative alternative ideas and green practices emerge (Smith, 2006). Hofman et al. (2004) underscore that sociotechnical transitions and innovations' scale-up occur through several phases. In food systems, these phases are the following: In the first phase, novel entrants and novelties emerge in the interstices of the existing regime to address some of its negative externalities. In the second phase, niche actors improvise, engage in experiments, and explore ways to meet potential consumers' demand. The initial market implementation frequently occurs in small and specialized markets (e.g., farmers' markets, community supported-agriculture, etc.) (Lamine et al., 2015). In the third phase, as the niche becomes established, it structures and reinforces itself with one of the following three growth strategies (Smith and Raven, 2012):

- A fit-and-conform strategy that entails designing innovations that fit the regime's industrial norms.

- A stretch-and-transform strategy consists to create capabilities to attract regime actors more favourably towards investments in niches solutions.

\footnotetext{
${ }^{1}$ Aria: Regional association for the development of agri-food industries.

Cervia: Regional center for the valorization of innovations in food industries.

${ }^{2}$ Engineering College for Living Sciences, Industries and Environment (Paris, Université Paris-Saclay).
} 
- A fit-and-stretch strategy consists of several types of decision-making rubrics that are meant to create an advantage(s) for the organization. Examples of these could be developing a higher-quality product to an established distribution channel (Naoum, 2001), or even transforming the prevailing regime (Hoogma et al., 2002).

These strategies shape the transition paths that SFSs can follow and demand innovative capabilities and strategic niche management processes (Kemp et al., 2001; Schot and Geels, 2008) with the goal of maintaining their own values and capabilities, or integrating and hybridizing with the dominant food system (Ingram, 2015). These processes include the development of technical improvements, supportive infrastructure, improved communication and understanding of consumer demand, knowledge and resources sharing, and experimentation and demonstration of sustainable food projects, understanding of the social and environmental consequences of various practices, and/or appropriate production and distribution networks modes (El Bilali and Probst, 2017).

To explore the sustainability innovations and paths of four firms implementing the short food system paradigm and the links that can be established between their sustainability strategies, these innovations and their territory, we focus in each case on two dimensions:

1. The technical and social innovations of these food systems and how, at their scale, they contribute to a regional ecological transition.

2. The interactions and alignment of these SFSs with the existing regime and landscape.

\section{Methodology - data collection}

For our case studies we used secondary and primary data sources. First, we studied the existing documentation about the innovation challenges, opportunities, weaknesses and threats of food systems in the Paris region (Agreste, 2017; Rapport de la Mairie de Paris, 2018). Second, between June and October 2019 we conducted four semi-directive interviews with three dairy firms and one vegetable-processing cooperative, designed as short food systems. We focus on yoghurt consumption because of its economic importance for French food industries and for French consumers. According to Fisberg and Machado (2015) more than one third of the population consumes at least 5 servings each week. Interviews were guided by an interview protocol that probed the respondents regarding the social and technical innovations that they developed (See Table 1). Each interview was approximately $1-1 / 2$ hours.

Table 1. The main interview topics

\begin{tabular}{|l|l|}
\hline Sociotechnical variables & Topics \\
\hline Farming practices & Cropping systems, agro-chemicals used in the farming system \\
\hline Technologies, processes, tools & Energy, processes for product/value creation, life cycle analysis \\
\hline Distribution channels & Parameters, reasons for the choice of the distribution channels \\
\hline Value proposition & Sustainability of value proposition \\
\hline Key customers/consumers & Main requirements, demands and needs \\
\hline Communication channels & Methods for communicating with partners \\
\hline Learning, co-creation & Training sessions, forms of knowledge sharing with stakeholders \\
\hline Supportive local authorities & Advice, knowledge and expertise transfer, financial aid \\
\hline Packaging & Techniques and recycling \\
\hline Goals & Drivers and obstacles to achieving goals \\
\hline Organizational & Use of contracts, logistics, etc. \\
\hline Institutional & Standards, labels, collective rules governing the supply chain \\
\hline
\end{tabular}




\section{The short food systems case studies}

\subsection{Grignon farm - local milk, traditional yoghurt and biogas}

Grignon farm is historically attached to AgroParisTech ${ }^{3}$ (since 1826) as an experimental farm and a domain for research and knowledge production and sharing in agriculture. Over the last 15 years, and in line with its mission in agri-food systems sustainability, the farm has undertaken a number of projects to increase the ecological value of its localization through energy consumption. For example, to decrease its off-farm energy consumption it implemented a demonstration platform, the Grignon Positive Energy programme. This project was designed to achieve two objectives. First, it aims better understanding, through experimentations, the impact of agricultural and food processing activities on the environment. Second, to share the technical, economic, and environmental innovation results developed in the farm with other farms and business professionals. This knowledge sharing practice aims to show that energy system transition is technically feasible and economically viable. One of the farm's ecological innovations is the installation of a biogas digester that transforms the livestock waste into biogas. This biogas is used to pasteurize its milk, produce hot water, and power the farm's heating system. As biogas produced is more important than the farm's needs, in 2019 the farm contracted to deliver its biogas to the regional natural gas pipe. These innovations allowed the farm acquiring the high environmental certification (HVE3). In 2014 as part of its transition programme, Grignon farm created a partnership with three local dairy farms and a milk processer, to produce a local milk and yoghurt distributed in various regional channels.

\subsection{Farm V - ecological 'Bleu-Blanc-Coeur' milk and yoghurt}

Since 2014 the farm's main agro-ecological transition strategy is to supply healthy yoghurts to local consumers labelled 'Bleu-Blanc-Coeur'. This label means that the yoghurt is naturally enriched with Omega-3 fatty acid, considered as a health factor in western countries (Denis et al., 2013).

This nutritional value is obtained by a sequence of interrelated technical production practices that improve not only the nutritional values of the yoghurt, but also the animal and social impacts of the product's life cycle. First, the farm feeds its cows linseed naturally rich in Omega 3 fatty acids. The linseed is prepared by a process of thermo-extrusion to increase its digestibility, and hence, increase animals' health. Second, the yoghurt produced from this milk has positive nutritional and health impacts as many people have diets that are low in omega-3 (Harvard medical school report, 2013). This yoghurt is distributed through fine food product boutiques and institutional food providers including corporate, school and university canteens. Finally, Farm V participates in a regional carbonoffset programme through which it obtains the neighbouring farms manure as "carbon credits" and repurposes them in ecological solutions such as 'storage' in the farm's soils.

Recently, the farm improved the yoghurt's nutritional values by decreasing salt and sugar ingredients in processing to adapt to these societal requirements and align with the national nutritional programme recommendations (PNNS).

\subsection{Start-up Y - local organic Greek yoghurt}

This start-up was established in 2013 by two friends that decided to transform conventional milk locally produced into "Greek" yoghurt. The first business model was designed to sell this yoghurt in the regional farmers' markets. Despite its premium price, this yoghurt received a great attention from regional and social media. In its marketing the entrepreneurs focused on the local embeddedness of their product's "content" which relates to the main cultural and technical innovation implemented into their yoghurt to attract and retain the target customers and consumers. This strategy focused on the locally and socially inclusive network of actors surrounding the business model and the nutritional particularities of drainage of cheese curds specific to Greek yoghurts. These are strained through a cheesecloth that removes most of its whey and result in a thick texture and high protein content. This process allowed the introduction of new healthy yoghurt in the local food markets. To satisfy the increasing demand for local and organic yoghurts, the two entrepreneurs redesigned their business model

\footnotetext{
${ }^{3}$ AgroParisTech is the former Institut National Agronomique - Paris-Grignon (INA-PG)
} 
and invested in a larger automated processing plant and changed both their milk suppliers (from conventional to organic milk) and distribution system (from farmers' market to supermarkets). By shifting to a more sustainable system and meeting stringent technical and industrial standards, the startup scaled up very quickly to supply institutional food providers including corporate, school and university canteens, conventional supermarkets, and the French railroad lines' catering service (SNCF). The social dimensions of the innovation are related to three practices:

- Yoghurt produced is clean label product (i.e. they have no added sugar, no preservatives or artificial additives). The packaging labels are fixed by regional workers from ESAT (Établissement et Service d'Aide par le Travail), a company that help handicapped people integrate real workplaces.

- Partner farm approach. This is a local solidarity distribution convention, which aims linking economic and locally produce in one distribution system. In other words, the boutique of this farm sells the products of other regional producers (wheat, lentils, honey) and processors (beer, cheese, sausages...), gets a margin profit, and helps local shoppers reduce their transportation between farmers.

\subsection{Start-up L - organic 'ready-to-cook' vegetable processor}

In 2010, the French green spaces agency bought a farm (145 ha) via the SAFER (Land and Rural Development Society) and partnership with the Seine Normandy Water Agency and the Regional Council Ile-de-France (IDF). The objective of this purchase is to maintain on this land, under which lies a catchment area of drinking water, an agricultural activity respectful of the environment, soil, water, and humans' health. The Start-up L was established on this land in 2012, by an organic carrot producer, at the intersection of two opportunities: The first was that large food catering firms needed large volumes of organic and local vegetables that were vacuum-packed and ready to use in institutional food kitchens. Second, organic farmers in the Paris region were widely scattered and could not individually provide the quantity and standards needed of vacuum-packed vegetables. To articulate these two facts, this farmer contracted with a multinational company specialized in collective catering distribution to develop a "vegetable processor" as a solution or service that would supply caterers with vegetables produced organically and locally. In return, this multinational company committed to purchase and sell all of his production. To facilitate this business, a cooperative was created, and 25 organic farmers and their municipalities were committed to supply the cooperative with their produce.

The design of this cooperative was meant to diversify the organic supply to be processed, support the Île-de-France organic farmers, create for them a new market, improve their income, mutualize investment costs, and work in cooperation with various local government organizations. With these promises the cooperative design gathered a diversity of actors with divergent interests to build a sustainable food system aligned with Food Egalim law principles at three levels of sustainability:

- Economic: Paying fair prices to local organic producers, allowing them to ensure a decent living through a better value sharing.

- Environmental: Reinforcing soil structure and regional biodiversity through environmentally friendly agricultural practices.

- Social: Diffusing nutritional and healthy products to a large number of the regional population. The cooperative now supplies institutional food providers such as school and workplace canteens and a chain of organic shops.

Table 2 summarizes the local production and distribution strategies of these short food systems, the technical and social innovations they have implemented and their contribution to the Île-de-France ecological transition.

\section{Discussion and conclusions}

Cases analysis identified four sociotechnical innovation drivers: localism, organic, and organoleptic novelties for start-up Y; secured commercialization for the vegetable's processor L; agro-ecology and environmentally friendly technologies for Grignon Farm; and nutrition and health for the Farm V. Each of these firms tried to anchor these innovations with a territorial development objective (see Table 2). 
Table 2. Short food systems strategies, sociotechnical innovations and contribution to regional ecological transition

\begin{tabular}{|c|c|c|c|c|}
\hline 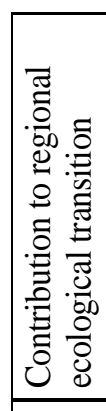 & 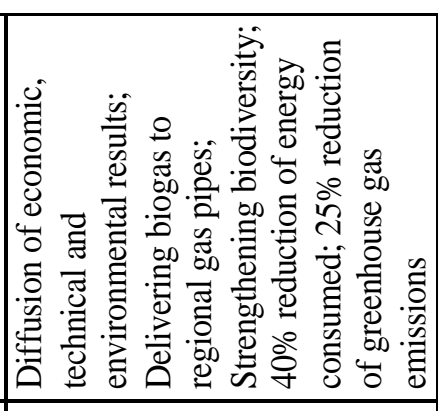 & 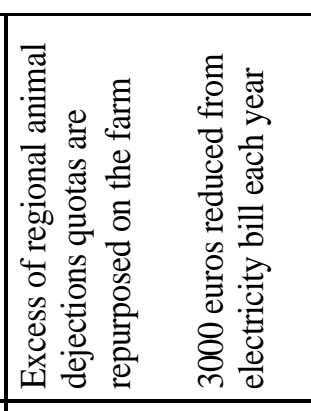 & 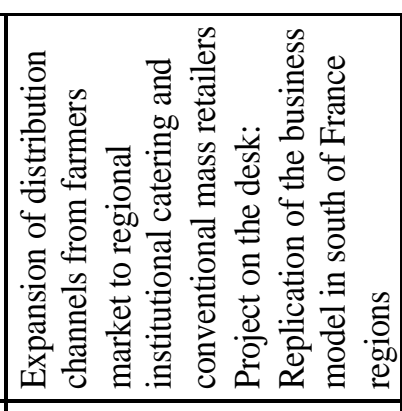 & 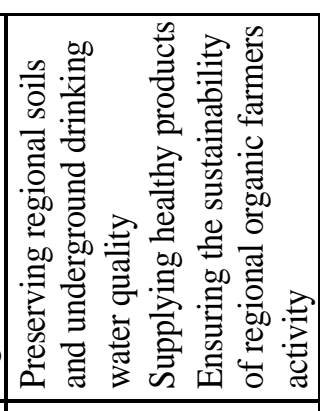 \\
\hline 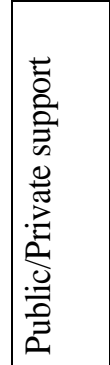 & 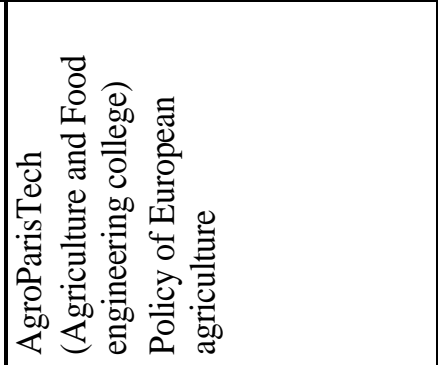 & 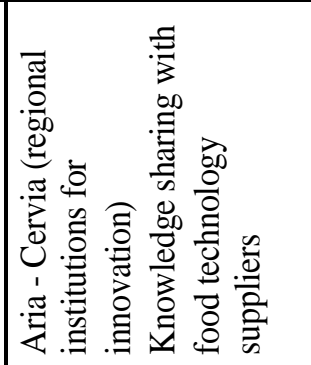 & 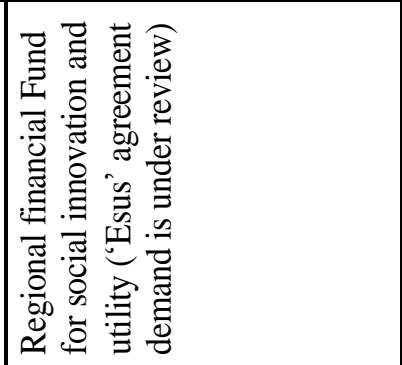 & 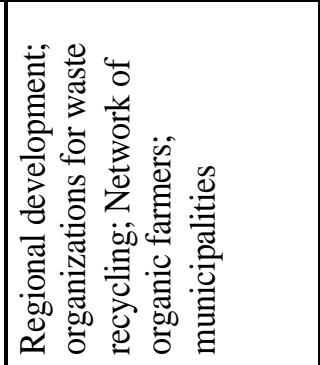 \\
\hline 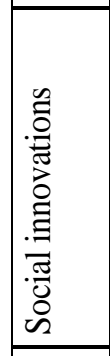 & 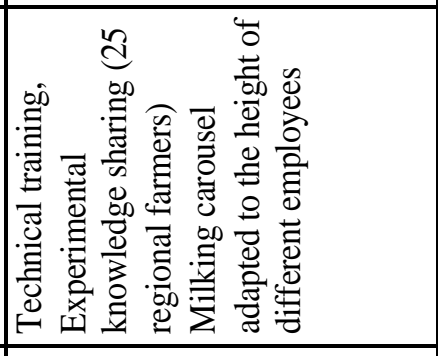 & 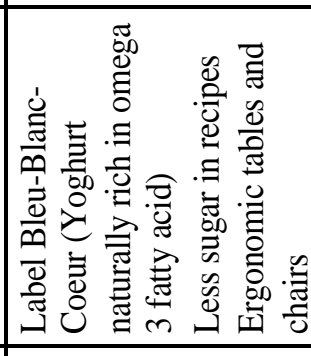 & 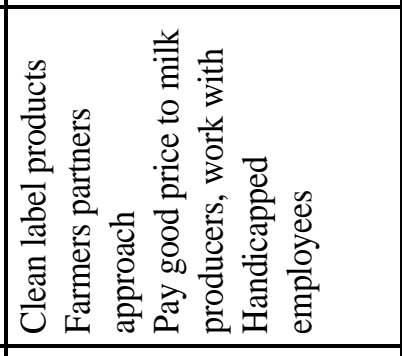 & 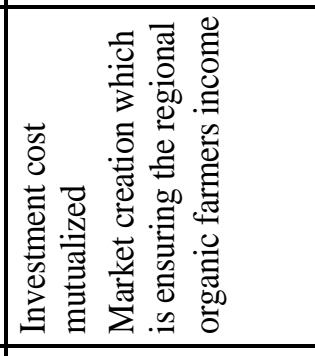 \\
\hline 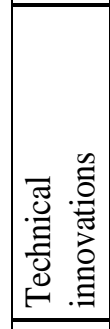 & 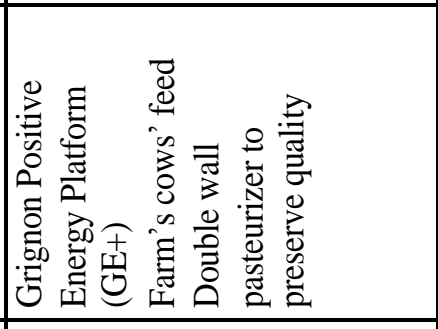 & 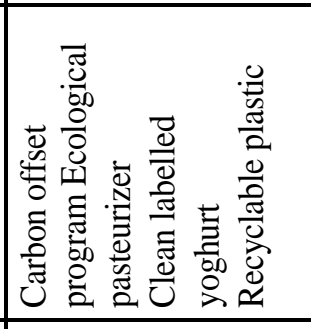 & 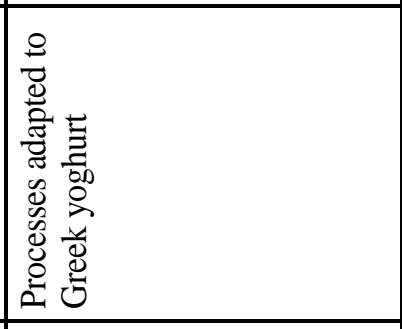 & 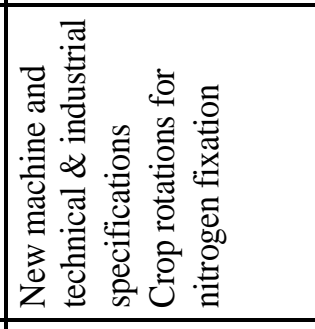 \\
\hline 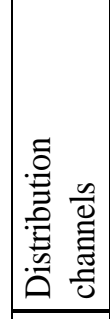 & 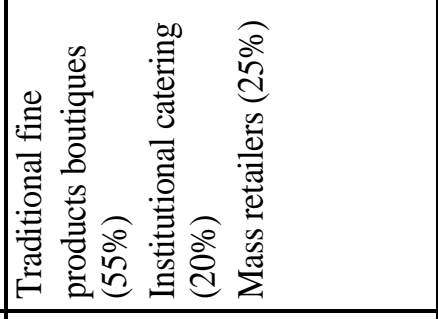 & 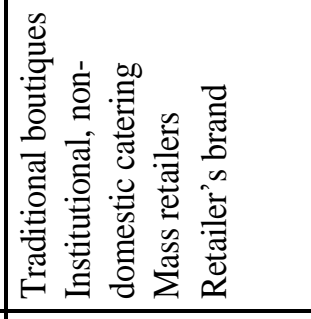 & 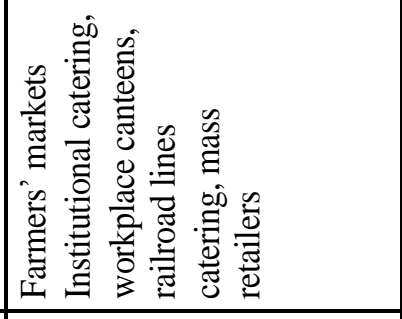 & 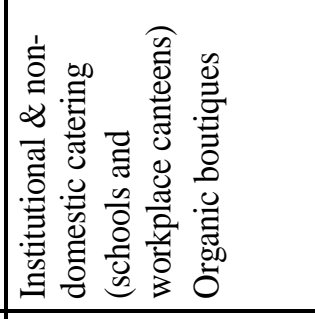 \\
\hline 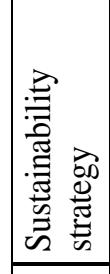 & 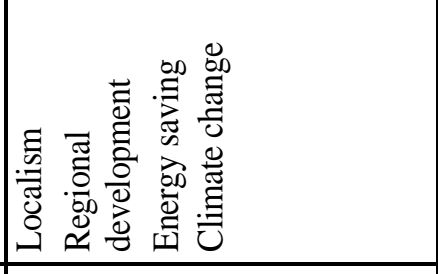 & 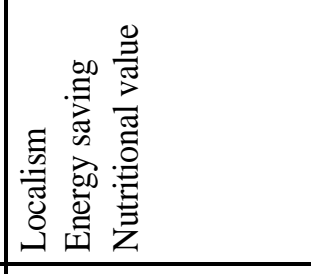 & 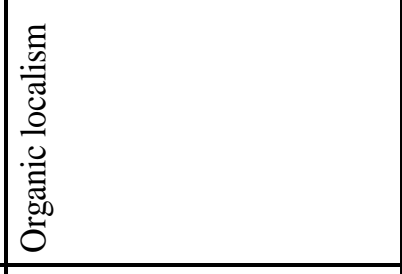 & 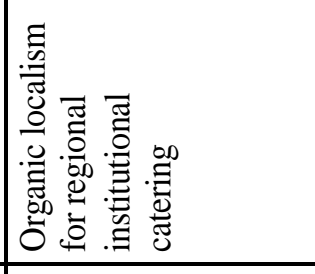 \\
\hline 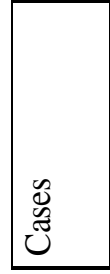 & 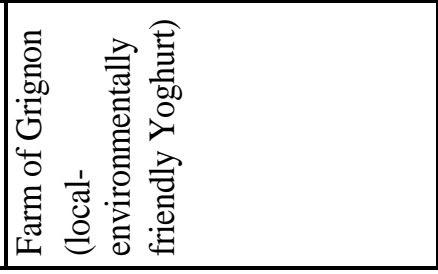 & 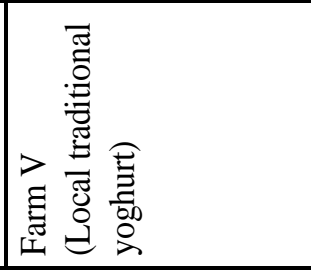 & 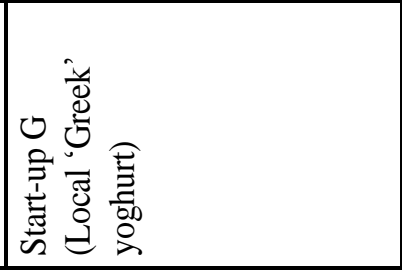 & 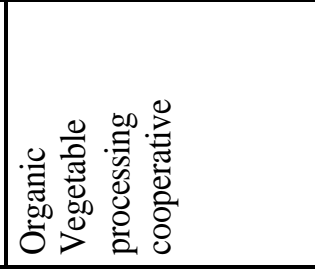 \\
\hline
\end{tabular}


The research analysis also identified four pathways that were used by food niche actors (acting as new entrants to food market) to design the SFSs strategies. These pathways are: (a) energy transition system for Grignon farm, (b) nutritional transition system for farm V, (c) sustainable work conditions and product's quality through localism for start-up Y, and (d) socio-economic and environmentally friendly practices for vegetable processor L. To illustrate, Grignon farm adopted two strategies. The stretch-and-transform strategy that is expressed through its efforts to develop environmentally friendly innovations, create new knowledge related to energy transition systems and then diffuse them to regional farmers and other actors of food value chain. Grignon farm also employed the fit-and-stretch strategy through its decision to distribute its milk in established conventional supermarkets. However, its economic equilibrium is also based on the development of its sales of local products and its service offering. As example, Grignon Farm transforms one third of $\mathrm{V}$ farm milk with its traditional recipe. Farm V also used a fit-and-stretch growth strategy by developing and distributing locally its naturally enriched omega 3 fatty acids yoghurts. Start-up $\mathrm{Y}$, in contrast, began in its protected niche and evolved with a fit-and-conform strategy by producing organic and conventional local yoghurts for a variety of markets, not all of which were local. As for Grignon and V farms, by introducing its products to institutional canteens, Start-up Y participates through a stretch-and-transform strategy to an existing system transformation. Finally, the vegetable processor L, also through a stretch-and-transform strategy, designed its whole system from vegetable production, to processing and distribution to provide organic farmers with a market and income, while supplying only institutional catering and organic shops.

This cross-sectional analysis of the four cases shows that in all these configurations these organizations mobilize several transition strategies. Under the impulse of the Egalim law, they manage to participate in "stretch-and-transform" strategy. However, the financial income that rewards these activities is insufficient to ensure the economic balance of their business model. This situation occurs in spite of the involvement of external actors (actors of the dominant regime but also representatives of municipalities or environmental protection) who support the development of these activities. The dimensioning of small production facilities, the need to develop processing and distribution knowledge, the multiplication of activities they have to manage as a result, are cost factors that position the offering of these 'neoactors' on restricted market segments, forcing them to multiply the distribution channels in order to achieve an economic balance.

Finally the innovations' systemic nature developed by some of these organizations (e.g. Vegetable processor) seems to rely on an organized mobilization of several actors belonging to what Meynard et al. (2016) define as coupled innovations processes, i.e. innovations that are designed to involve a collective of actors and systems, such as agriculture, distribution, processing, consumers, research institutions, norms and standards, and other stakeholders, engaged in change debates, investing resources and pushing for a systemic transformation.

However, in the different cases studied, the trajectory of these FSS is positively influenced by the recent French Egalim law, which encourages the deployment of a more sustainable food supply in public canteens. It therefore creates a relatively favourable configuration for these niches to participate in the ecological transition, particularly if we consider their action not independently of each other, but in conjunction with each other. Yet, the study shows that the strategies currently developed by these organisations reflect unstable states that lead them to build and develop several business models in parallel. The upcoming years will determine whether the ecological innovations developed in these projects actually enable them to transform food dominant systems that are not conducive to ecological transition, or remain the source of niche markets that are certainly interesting, but whose limited scope precludes any ambition for ecological transition.

\section{Acknowledgements}

We would like to thank the innovation chair of AgroParisTech-Université Paris Saclay for financing this project.

\section{References}

Agreste (2017), "IAU -Île-de-France, Une métropole à la table- L'île de France face aux défis alimentaires", Paris, France, Available at: http://agreste.agriculture.gouv.fr/IMG/pdf/101_IAURIF_Une_metropole_a_ ma_table.pdf 
Denis, I. et al. (2013), "Oméga-3 fatty acids and brain resistance to ageing and stress: Body of evidence and possible mechanisms”, Ageing Research Reviews, No. 12, pp. 579-594. https://https://dx.doi.org/10. 1016/j.arr.2013.01.007

El Bilali, H. and Probst, L. (2017), "Towards an integrated analytical framework to map sustainability transitions in food systems", Agrofor International Journal, No. 2, pp. 24-32.

European Commission (2013), "Short food supply chains and local food systems in the Eu. A state of play of their socio-economic characteristics", Available at: https://ec.europa.eu/jrc/en/publication/eur-scientific-and-technicalresearch-reports/short-food-supply-chains-and-local-food-systems-eu-state-play-their-socio-economic

FAO (2018), "Sustainable Food systems", Available at: http://www.fao.org/3/ca2079en/CA2079EN.pdf

Fournier, S. and Touzard, J. (2014), "La complexité des systèmes alimentaires : Un atout pour la sécurité alimentaire?", Vertigo, Vol. 14 No. 1, pp. 1-20.

Fisberg, M. and Machado, R. (2015), "History of yogurt and current patterns of consumption", Nutrition Reviews, Vol. 73 No. Supplement, pp. 4-7. https://doi.org/10.1093/nutrit/nuv020

Geels, F.W. (2004), "From sectoral systems of innovation to socio-technical systems. Insights about dynamics and change from sociology and institutional theory", Research Policy, Vol. 33 No. 6-7, pp. 897-920. https://doi.org/10.1016/j.respol.2004.01.015

Harvard Health Publishing (2013), "Omega-3-rich foods: Good for your heart, Harvard School", Available at https://www.health.harvard.edu/heart-health/omega-3-rich-foods-good-for-your-heart

Hoffman, J. and Loeber, A. (2016), "Exploring the Micro-politics in Transitions from a Practice Perspective: The Case of Greenhouse Innovation in the Netherlands", Journal of environmental Policy Plan, Vol. 18 No. 5, pp. 692-711. https://doi.org/10.1080/1523908X.2015.1113514

Hofman, P.S., Elzen, B.E. and Geels, F.W. (2004), "Sociotechnical scenarios as a new policy tool to explore system innovation: co-evolution of technology and society in the Netherlands's electricity domain", Innovation: Management, policy \& Practice, Vol. 6, pp. 344-360.

Hoogma, R. (2002), "Experimenting for Sustainable Transport", The Approach of Strategic Niche Management, Spon Press, London-Transport, development and sustainability.

Ingram, J. (2015), "Framing niche-regime linkage as adaptation - An analysis of learning and innovation networks for sustainable agriculture across Europe", Journal of Rural Studies, No. 40, pp. 59-75. https://doi.org/10.1016/j.jrurstud.2015.06.003

Kemp, R., Rip, A. and Schot, J. (2001), "Constructing transition paths through the management of niches", In: Garud, R. and Karnøe, P. (Eds.), Path Dependence and Creation, Lawrence Erlbaum, London.

Lamine, C. et al. (2015), "Agri-Food systems and territorial development: Innovations, new dynamics and changing governance mechanisms”, In: Farming Systems Research into the 21st Century: The New Dynamic; Darnhofer, I., Gibbon., D., Dedieu., B., dir., The farming systems approaches into the 21 st century, Springer.

Meynard, J.-M. et al. (2016), "Designing coupled innovations for the sustainability transition of agrifood systems", Agricultural systems, Vol. 157, pp. 330-339. http://dx.doi.org/10.1016/j.agsy.2016.08.002

Naoum, S. (2001), People and organizational management in construction, Thomas Telford, London.

Rapport de la mairie de Paris (2018), Stratégie de Paris pour une alimentation durable, Mairie de Paris, France. Available at: https://www.paris.fr/pages/la-strategie-de-paris-pour-une-alimentation-durable-5234

Rastoin, J. and Ghersi, G. (2010), "Le système alimentaire mondial: concepts et méthodes, analyses et dynamiques", Éditions Quae, Paris, France.

Schot, J. and Geels, F.W. (2008), "Strategic niche management and sustainable innovation journeys - Theory, findings, research agenda, and policy”, Technology Analysis and Strategic Management, Vol. 20 No. 5, pp. 537-554. https://doi.org/10.1080/09537320802292651

Serhan, H. and Yannou-LeBris, G. (2020), "The engineering of food with sustainable development goals: policies, curriculums, business models, and practices", International Journal of Sustainable Engineering. https://doi.org/10.1080/19397038.2020.1722765

Smith, A. (2006), "Green niches in sustainable development: the case of organic food in the United Kingdom Environment and planning", Government and Policy, Vol. 24, pp. 439-458. https://journals.sagepub. com/doi/pdf/10.1068/c0514j

Smith, A. and Raven, R. (2012), "What is protective space? Reconsidering niches in transitions to sustainability", Research Policy, Vol. 41 No. 6, pp. 1025-1036. https://doi.org/10.1016/j.respol.2011.12.012

Yannou-LeBris, G. et al. (2019), Ecodesign and ecoinnovation in the food industries, ISTE Ltd London - Wiley Publishing, Hoboken, NJ, USA. 